\title{
Market Selling Conditions and Storage Methods Influences $\beta$-carotene Stability and Retention in Biofortified Gari
}

\author{
Cosmos Ifeanyi Onyiba*, Simeon Ikechukwu Egba
}

Department of Biochemistry, College of Natural Sciences, Michael Okpara University of Agriculture, Umudike, P.M.B. 7267, Umuahia Abia State, Nigeria

* Corresponding Author email: cosmos.onyiba@gmail.com

Article History

Received: 30 January 2020

Revised: 11 April 2020

Accepted: 21 April 2020

Published: 22 April 2020

Student(s)

- Cosmos Ifeanyi Onyiba

Academic Year: 2016-2017

Course Level: Master

Course Name: M.Sc. (Biochemistry)

Course year: $2^{\text {nd }}$ Year

Mentor(s)

- Simeon Ikechukwu Egba

\begin{abstract}
The influence of regular market selling conditions and storage methods on $\beta$-carotene stability and retention were investigated in two different biofortified gari types. Freshly processed gari samples obtained from TMS 01/1412 and TMS 01/1371 respectively were exposed to $35-45^{\circ} \mathrm{C}$ sunlight (ESL) and 60 watts electric bulb light (EEB); stored in black polyethylene bag (SPB) and air-tight aluminum container (SAC) respectively. The stability (using area under curve analysis) and retention (\%) of $\beta$ carotene in all the experiments were monitored and compared over a period of 4 weeks. Results revealed that ESL had a huge negative influence on the stability and retention of $\beta$-carotene in the two biofortified gari types. Although EEB showed minimal but progressive negative influence, SAC followed by SPB showed the least negative influence on the nutrient stability. The overall retention of $\beta$-carotene in gari processed from TMS 01/1412 and TMS 01/1371 respectively were as follows: ESL $(12.1 \%, 12.8 \%)$, EEB (58.5\%, 47.5\%), SPB (61.9\%, 50.8\%) and SAC $(60.2 \%, 82.6 \%)$. SAC retained the most appreciable amount of the nutrient thus suggesting it as a better form of storage while ESL lost the largest amount of the nutrient thus portraying it a detrimental market selling condition for the biofortified gari.
\end{abstract}

Keywords: $\beta$-carotene, Biofortified, Gari, Market selling, Storage stability, Retention

\section{Introduction}

Vitamin A deficiency (VAD) has remained epidemic especially in many Sub-Saharan countries [1]. This, as a consequence, has led to the increased risk of individual susceptibility to diseases related to poor immunity as well as impairment of vision [2]. As a strategy, biofortification through conventional breeding has been employed to incorporate and increase the concentration of $\beta$-carotene in cassava. This has been proven an effective strategy since cassava is one of the staple crops consumed in the VAD endemic regions such as Africa [3]. Cassava (Manihot esculenta Crants), also known as manioc, yucca or tapioca, is cultivated annually in the tropical and sub-tropical regions of the world [4]. It is estimated that about 277 million metric tonnes of cassava are produced annually in world and this serves as staple food for over 500 million consumers 
[5]. Statistics also shows that Nigeria is the largest producer of cassava in the world with about 57 million metric tonnes [5]. As at 2001-2003, cassava consumption in Nigeria was approximately 200-250 g/day among children 4-6 years old and 350-400 g/day among women in the southern part of Nigeria [6]. In Africa, Brazil and Southeast Asia, cassava is majorly processed into gari which makes it the highest cassava product consumed in the region [7].

Gari is a fermented and roasted cassava product that is obtained by following the successive steps of peeling, washing, grating, fermenting, sifting and roasting [8]. It is consumed as snacks and/or in form of a dough popularly known as "eba" in Nigeria, and it is major staple crop that feeds millions of Sub-Saharan Africans. Recently, gari processed from biofortified cassava has been documented by a study in Nigeria to be accepted by consumers who portrayed it to be good for eyesight and for children [9]. Unfortunately, the degradation of $\beta$-carotene in gari processed from biofortified cassava has been a major challenge to research as this threatens the product marketability as well as bioavailability of the nutrient in consumers. It has been established that pro-vitamin A carotenoids in cassava are liable to thermal (heat), photo (light) and oxidative (oxygen driven) degradation [10]. More also, the degradation of carotenoids in food crops such as maize [11], sweet potato [12] and gari processed from biofortified cassava [13] during storage have also been documented to be temperature and light driven. In Sub-Saharan Africa, gari is regularly sold in the market in a relatively harsh condition that exposes it to the "trio-conspirators" of carotenoid degradation (light, oxygen and temperature). In this regard, there is currently no scientific report on the influence of market selling conditions on the stability and retention of $\beta$-carotene in biofortified gari. Further, there seem to be no scientific report that recommends a clearly defined method of storage and/or packaging that would ensure maximum stability and retention of $\beta$-carotene in biofortified gari. It is against these aforementioned premises that we investigated the influence of regular market selling conditions and storage methods on $\beta$ carotene stability and retention in gari processed from biofortified cassava.

\section{Materials and Methods}

\subsection{Source of plant materials}

Propagative stems of two different biofortified cassava varieties (TMS 01/1412 and TMS 01/1371) were obtained from HarvestPlus Unit at the International Institute of Tropical Agriculture (IITA), Ibadan, Oyo State, Nigeria.

\subsection{Planting, harvesting and processing of biofortified cassava roots}

The varieties were planted separately in a farmland at Umuariaga Village, Umudike, Abia state, Nigeria and were harvested after 12 months. Freshly harvested cassava roots from the respective varieties were peeled, washed, grated, dewatered (with 48 hours fermentation), sifted, roasted and sieved to obtain the gari.

\subsection{Experimental design and sample collection}

Samples of gari obtained from the respective biofortified cassava variety were subjected to regular market selling conditions as follows: exposure to sunlight (ESL) (out-door) and exposure to 60 watts electric bulb light (EEB) (in-door). In another experiment, gari samples processed from each biofortified cassava variety were placed in storage systems (in-door) as follows: storage in black polyethelene bag (SPB) and storage in air-tight aluminum container (SAC). Samples of each biofortified gari were collected weekly (for a duration of 1 month) from the various experiments for the determination of their $\beta$-carotene concentrations.

\subsection{Determination of $\beta$-carotene concentration}

The $\beta$-carotene (Pro-vitamin A) content of collected samples was determined by spectrophotometry following the method described by Umeh and Ogbuagu [14]. In brief, one gram of sample with $10 \mathrm{ml}$ of acetone was dissolved in $50 \mathrm{ml}$ conical flask, allowed to stand for 20 minutes, and was gently shaken at 4 minutes interval in order to efficiently extract the coloured substance in the sample. After settling, the clear solution was obtained by decanting into a test tube. About $5 \mathrm{ml}$ of hexane was added to separate the solution 
Onyiba et al., Adv. J. Grad. Res.; Vol. 8, Issue 1, pp: 58-67, July 2020

into two distinct layers. The upper layer was obtained using a separating funnel, and collected in a test tube. Absorbance of the collected solution was then measured at $453 \mathrm{~nm}$ by spectrophotometry. The concentration of $\beta$-carotene in $\mu \mathrm{g} g-1$ was calculated as (Eq. (1)):

$\beta$ - carotene $\left(\mu \mathrm{g} g^{-1}\right)=\left(\frac{\text { Absorbance } * \text { Volume } * \text { Dilution factor }\left(10^{4}\right)}{\text { Absorption coef ficient of } \beta \text {-carotene }(2592)}\right.$

\subsection{Stability Profile}

Simple line charts were used to show the trend of changes of $\beta$-carotene concentration in the biofortified gari over a duration of 4 weeks. Area under curve (AUC) analysis was employed to compare the stability profiles of all the experiments. Total Area obtained from the AUC analysis was directly interpreted as the magnitude of stability of $\beta$-carotene in the biofortified gari.

\subsection{Retention of $\beta$-carotene}

Retention (\%) of $\beta$-carotene in the biofortified gari was calculated following the simple arithmetic equation (Eq. (2)) described by Bechoff et al. [12] as follows:

$R(\%)=\frac{\beta \text {-carotene content }\left(\mu g g^{-1}\right) \text { of gari during experiment }}{\beta \text {-carotene content }\left(\mu g^{-1}\right) \text { of gari before experiment }} \times 100$

\subsection{Statistical Analysis}

Data were analyzed on IBM SPSS 22 by t-test and one-way ANOVA (post hoc $=$ Bonferoni test) for the sake of comparisons. Graphpad prism 6.0.4 was used to plot descriptive charts. All comparison was done adopting $\mathrm{p}$ values less than 0.05 as significant.

\section{Results}

\subsection{Influence of ESL, EEB, SPB, and SAC on the concentration of $\beta$-carotene in gari processed from TMS 01/1412 Cassava}

The influence of exposure to sunlight (ESL), exposure to 60 watts electric bulb light (EEB), storage in black polyethylene bag (SPB) and storage in air-tight aluminum container (SAC) on the concentration of $\beta$ carotene in gari processed from TMS 01/1412 cassava within the duration of four weeks was investigated (Figure 1). ESL (with estimated temperature range of $35-45^{\circ} \mathrm{C}$ ) caused significant $(\mathrm{p}<0.05)$ reduction in the $\beta$-carotene concentration from baseline $(0.92 \pm 0.01 \mu \mathrm{g} g-1)$ to the first week $(0.25 \pm 0.01 \mu \mathrm{gg}-1)$ and second week $(0.12 \pm 0.01 \mu \mathrm{g} g-1)$, with non-significant $(\mathrm{p}>0.05)$ changes observed at the third $(0.12 \pm 0.01 \mu \mathrm{g} g-1)$ and fourth week $(0.11 \pm 0.01 \mu \mathrm{g} g-1)$ respectively (Figure $1 \mathrm{~A})$. EEB caused a significant reduction in the $\beta$ carotene concentration from baseline $(0.92 \pm 0.01 \mu \mathrm{g} g-1)$ to the first week $(0.71 \pm 0.01 \mu \mathrm{g} g-1)$, further significant reductions at second $(0.67 \pm 0.01 \mu \mathrm{gg}-1)$ and third week $(0.54 \pm 0.001 \mu \mathrm{gg}-1)$ and a non-significant change at the fourth week $(0.54 \pm 0.02 \mu \mathrm{g} g-1)$ (Figure 1B). SPB caused a significant reduction in the $\beta$ carotene concentration from baseline $(0.92 \pm 0.01 \mu \mathrm{g} g-1)$ to the first week $(0.79 \pm 0.02 \mu \mathrm{g} g-1)$, a nonsignificant change from the first to second week $(0.78 \pm 0.03 \mu \mathrm{g} g-1)$, and further reductions at the third $(0.64 \pm 0.02 \mu \mathrm{g} \mathrm{g}-1)$ and fourth week $(0.57 \pm 0.03 \mu \mathrm{g} g-1)$ respectively (Figure 1C). SAC caused a significant reduction in the $\beta$-carotene concentration from baseline $(0.92 \pm 0.01 \mu \mathrm{g} g-1)$ to the first week $(0.85 \pm 0.01 \mu \mathrm{g} g-1)$, further significant reductions at the second $(0.79 \pm 0.06 \mu \mathrm{g} g-1)$ and third week $(0.56 \pm 0.01 \mu \mathrm{g} g-1)$ and a non-significant change at the fourth week $(0.55 \pm 0.01 \mu \mathrm{g} g-1)$ (Figure 1D). 

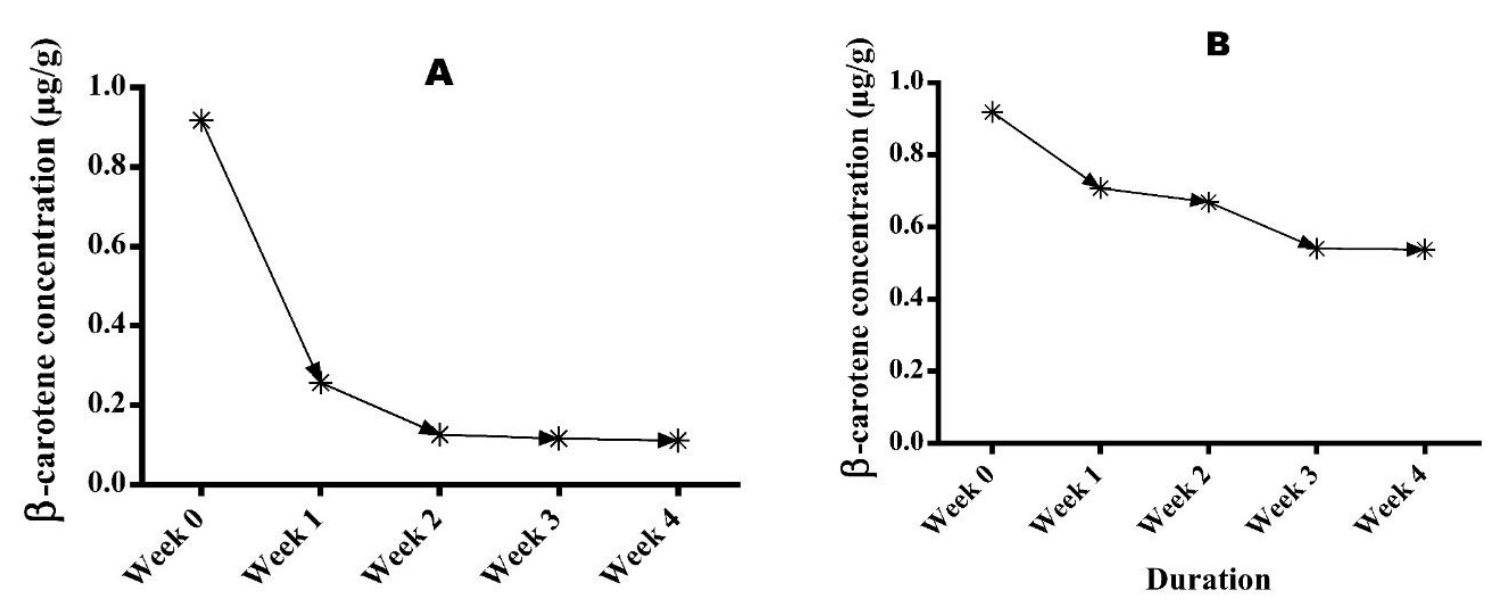

Duration
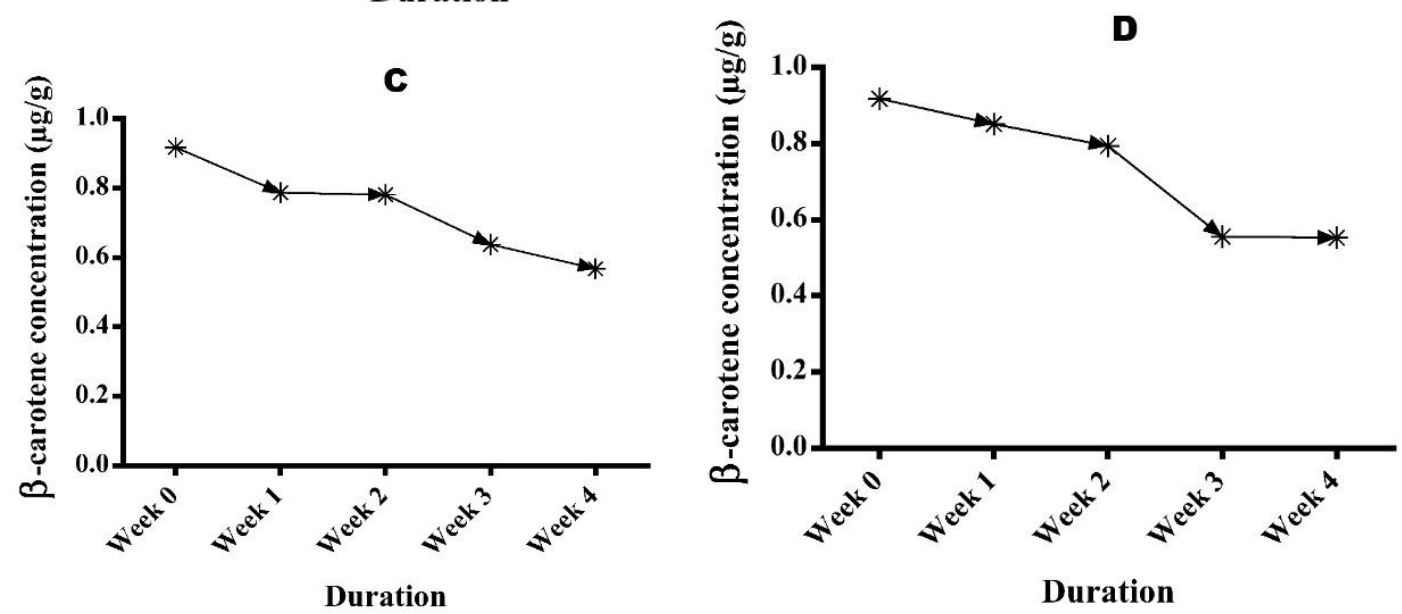

Figure 1: The influences of exposure to $35-45^{\circ} \mathrm{C}$ sunlight $(A)$, exposure of 60 watts electric bulb light $(B)$, storage in black polyethylene bag $(C)$ and storage in air-tight aluminum container $(D)$ on the concentration of $\beta$-carotene in TMS 01/1412 gari were determined over a 4 weeks period. Student's independent $T$-test was used to ascertain significant changes in the $\beta$-carotene concentration from week 0 to week 4 .

\subsection{Stability profile of $\beta$-carotene in TMS 01/1412 gari}

The overall stability of $\beta$-carotene in gari processed from TMS 01/1412 over a four weeks period of each experiment was estimated using the area under curve (AUC) analysis (Figure 2A). The area under curve for all experiments was in the order of ESL (1.014) < EEB (2.644) < SAC (2.936) < SPB (2.949). ESL portrayed the least stability while SPB showed the highest stability.

\subsection{Retention (\%) of $\beta$-carotene: TMS 01/1412 gari}

The percentage retention of $\beta$-carotene in gari processed from TMS 01/1412 over a four weeks period of all experiments were determined (Figure 2B). The percentage retention of $\beta$-carotene in the gari for each experiment was estimated weekly as follows: First week (ESL $(27.9 \pm 1.1 \%)$

$<\operatorname{EEB}(77.0 \pm 0.5 \%)<\mathrm{SPB}(85.7 \pm 1.5 \%)<\mathrm{SAC}(92.7 \pm 1.2 \%))$; Second week (ESL $(13.7 \pm 1.1 \%)<\mathrm{EEB}$ $(72.9 \pm 1.2 \%)<\mathrm{SPB}(85.1 \pm 2.9 \%)<\mathrm{SAC}(86.5 \pm 5.6 \%))$; Third week (ESL $(12.6 \pm 0.8 \%)<\operatorname{EEB}(58.8 \pm 0.8 \%)$ $<\operatorname{SAC}(60.5 \pm 1.3 \%)<\mathrm{SPB}(69.5 \pm 2.4 \%))$; Fourth week (ESL $(12.1 \pm 0.1 \%)<\mathrm{EEB}(58.5 \pm 1.6 \%)<\mathrm{SAC}$ $(60.2 \pm 1.2 \%)<\mathrm{SPB}(61.9 \pm 2.5 \%))$. Overall, ESL significantly $(\mathrm{p}<0.05)$ had the least retention while there were no statistical differences $(p>0.05)$ in retention capacities of EEB, SPB and SAC at the fourth week of the experiment. 

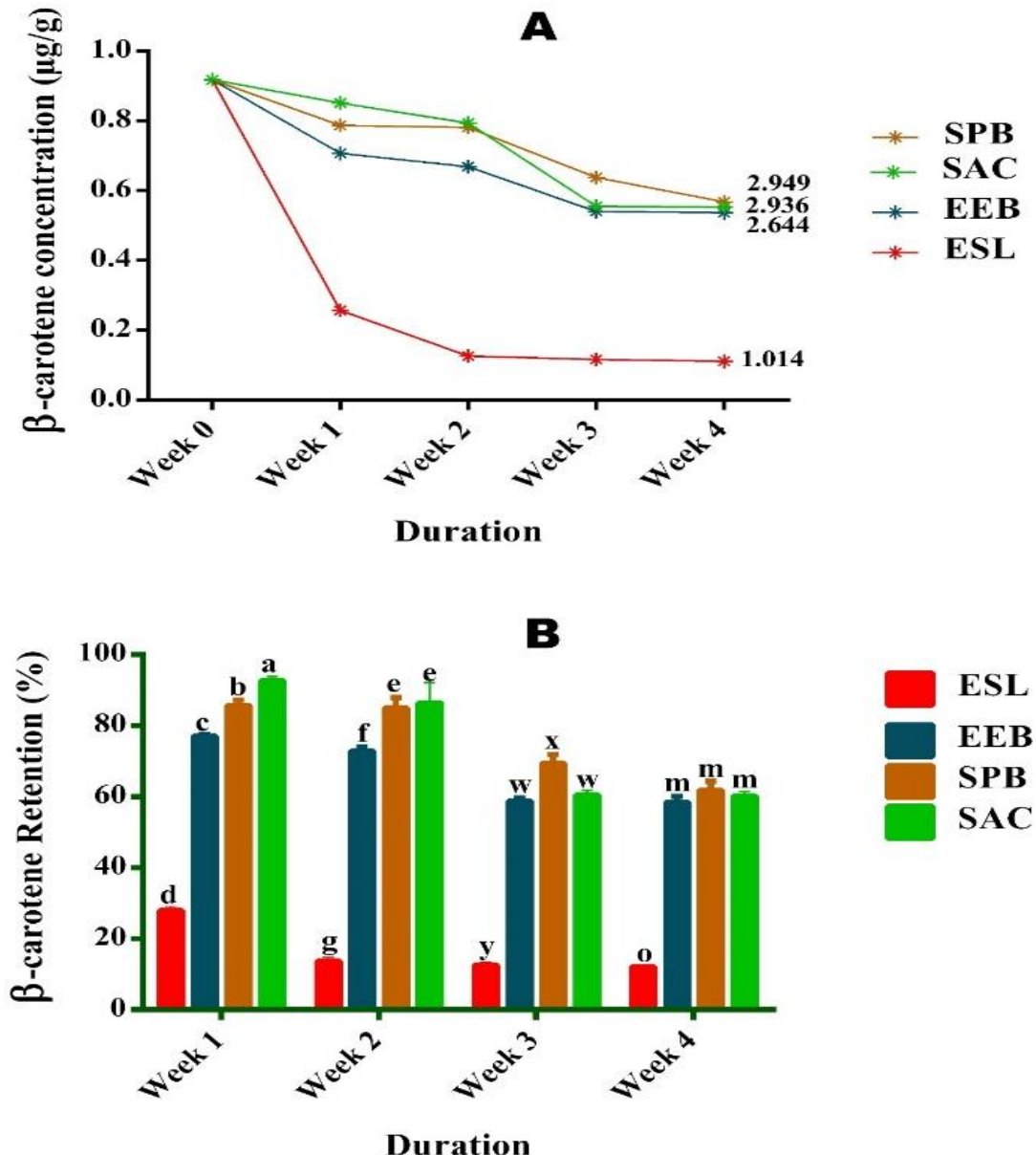

Figure 2: The stability profile of $\beta$-carotene in TMS 01/1412 gari (A) showing the total area under curve of exposure to $35-45^{\circ} \mathrm{C}$ sunlight (ESL), exposure of 60 watts electric bulb light (EEB), storage in black polyethylene bag (SPB) and storage in air-tight aluminum container (SAC) over a 4 week period. The area under curve of each line is directly proportional to the stability of $\beta$-carotene in the biofortified gari. Comparison of the weekly retention of $\beta$-carotene $(B)$ in all the experiments was done using ANOVA (Post hoc: Bonferoni test; $p=0.05)$. Bars with same alphabet within each week are non-significantly $(p>0.05)$ different from each other.

\subsection{Influence of ESL, EEB, SPB, and SAC on the concentration of $\beta$-carotene in gari processed from TMS 01/1371 Cassava.}

The influence of exposure to sunlight (ESL), exposure to 60 watts electric bulb light (EEB), storage in black polyethylene bag $(\mathrm{SPB})$ and storage in air-tight aluminum container $(\mathrm{SAC})$ on the concentration of $\beta$ carotene in gari processed from TMS 01/1371 cassava over a four week period was investigated (Figure 3). ESL caused a significant $(\mathrm{p}<0.05)$ reduction in the $\beta$-carotene concentration from baseline $(1.41 \pm 0.02 \mu \mathrm{g}$ $\mathrm{g}$-1) to the first week $(0.38 \pm 0.03 \mu \mathrm{g} g-1)$ and further significant reductions from the second $(0.33 \pm 0.01 \mu \mathrm{g}$ $\mathrm{g}$-1) to the third $(0.25 \pm 0.002 \mu \mathrm{g} g-1)$ and fourth week $(0.18 \pm 0.01 \mu \mathrm{gg}-1)$ (Figure 3A). EBB (Figure 3B) and SPB (Figure 3C) respectively showed significant continuous reductions in the $\beta$-carotene concentration from baseline $(1.41 \pm 0.03 \mu \mathrm{g} g-1)$ to the first $(1.20 \pm 0.04,1.06 \pm 0.03 \mu \mathrm{g} g-1)$, second $(1.02 \pm 0.02,0.94 \pm 0.02$ $\mu \mathrm{g} g-1)$, third $(0.86 \pm 0.004,0.81 \pm 0.01 \mu \mathrm{g} g-1)$ and fourth week $(0.67 \pm 0.02,0.72 \pm 0.02 \mu \mathrm{g} g-1)$. SAC showed significant reductions in the $\beta$-carotene concentration from baseline $(1.41 \pm 0.02 \mu \mathrm{g} g-1)$ to the first week $(1.35 \pm 0.03 \mu \mathrm{gg}-1)$ and second week $(1.16 \pm 0.03 \mu \mathrm{g} g-1)$, and non-significant changes at the third $(1.16 \pm 0.03$ $\mu \mathrm{g} g-1)$ and fourth week (1.16 $\pm 0.05 \mu \mathrm{g} g-1)$ (Figure 3D). 


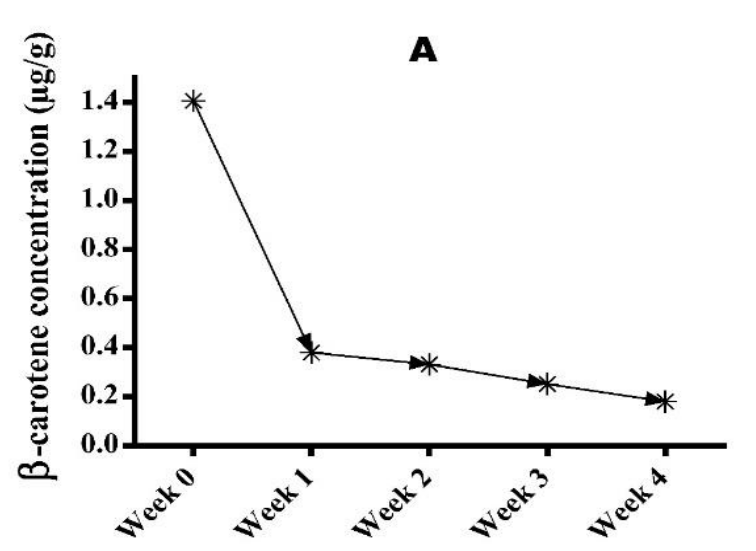

Duration

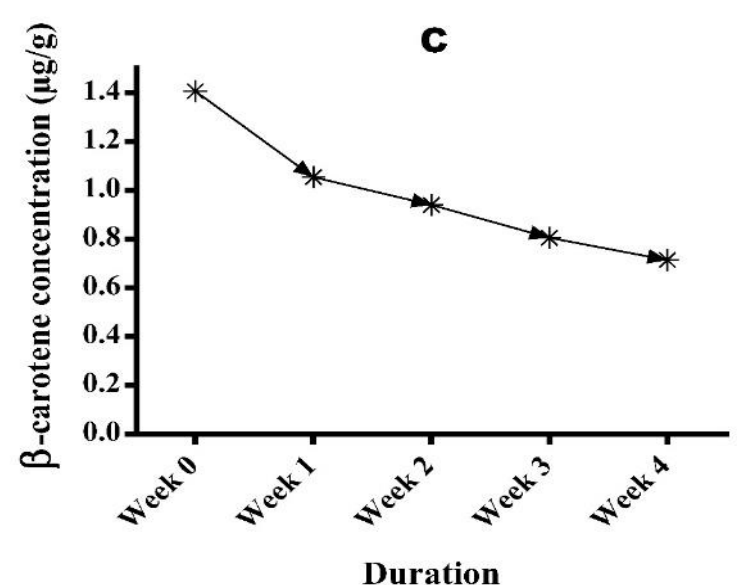

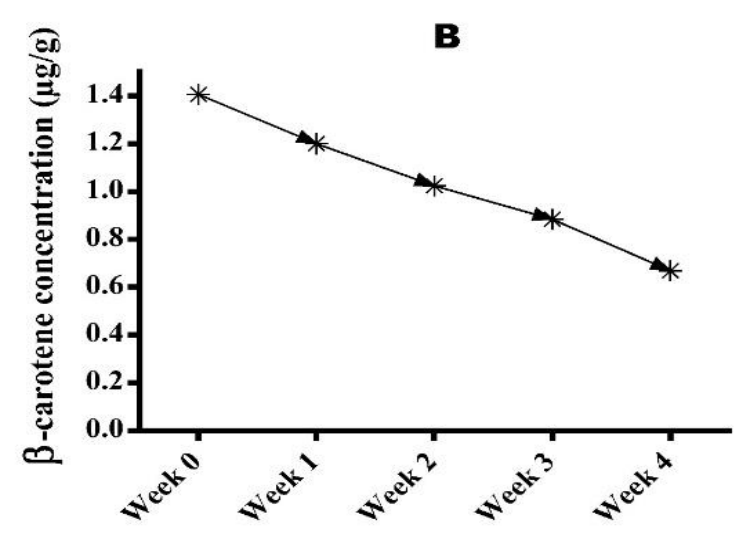

Duration

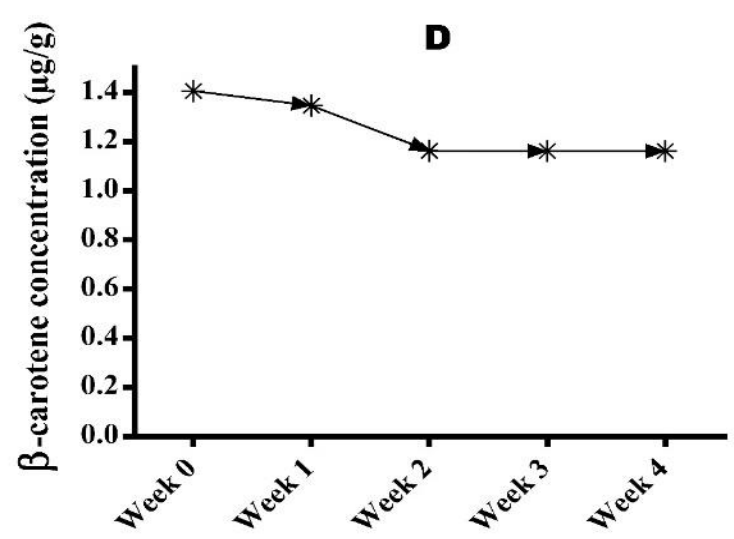

Duration

Figure 3: The influences of exposure to $35-45^{\circ} \mathrm{C}$ sunlight $(A)$, exposure of 60 watts electric bulb light $(B)$, storage in black polyethylene bag $(C)$ and storage in air-tight aluminum container $(D)$ on the concentration of $\beta$-carotene in TMS 01/1371 gari were determined over a 4 week period. Student's independent T-test was used to ascertain significant changes in the $\beta$-carotene concentration from week 0 to week 4.

\subsection{Stability profile of $\beta$-carotene in TMS 01/1371 gari}

The overall stability of $\beta$-carotene in gari processed from TMS $01 / 1371$ cassava over a four week period of all experiments were estimated using area under curve (AUC) analysis (Figure 4A). The area under curve for all experiments was in the order of ESL (1.759) < SPB (3.862) < EEB (4.148) < SAC (4.957). ESL portrayed the least stability while SAC showed the highest stability.

\subsection{Retention (\%) of $\beta$-carotene: TMS 01/1371 gari}

The percentage retention of $\beta$-carotene in gari processed from TMS 01/1371 cassava over a four week period of all experiments were determined (Figure 4B). The percentage retention of $\beta$-carotene in the gari for each experiment was estimated weekly as follows: First week (ESL $(27.1 \pm 2.9 \%)<$ SPB $(74.9 \pm 2.9 \%)<$ EEB $(85.4 \pm 3.9 \%)<$ SAC $(95.7 \pm 2.7 \%))$; Second week (ESL $(23.6 \pm 0.8 \%)<$ SPB $(66.9 \pm 1.6 \%)<$ EEB $(72.8 \pm 1.6 \%)<\mathrm{SAC}(82.7 \pm 3.1 \%)) ;$ Third week $(\operatorname{ESL}(17.9 \pm 1.6 \%)<\mathrm{SPB}(57.2 \pm 0.5 \%)<\operatorname{EEB}(62.9 \pm 0.4 \%)$ $<$ SAC $(82.6 \pm 3.1 \%))$; Fourth week (ESL $(12.8 \pm 1.2 \%)<$ EEB $(47.5 \pm 2.3 \%)<\mathrm{SPB}(50.8 \pm 1.9 \%)<\mathrm{SAC}$ $(82.6 \pm 4.7 \%))$. Overall, ESL significantly $(\mathrm{p}<0.05)$ had the least retention while SAC significantly had the highest retention. There was no significant $(\mathrm{p}>0.05)$ difference between the retention capacity of EEB and SPB. 

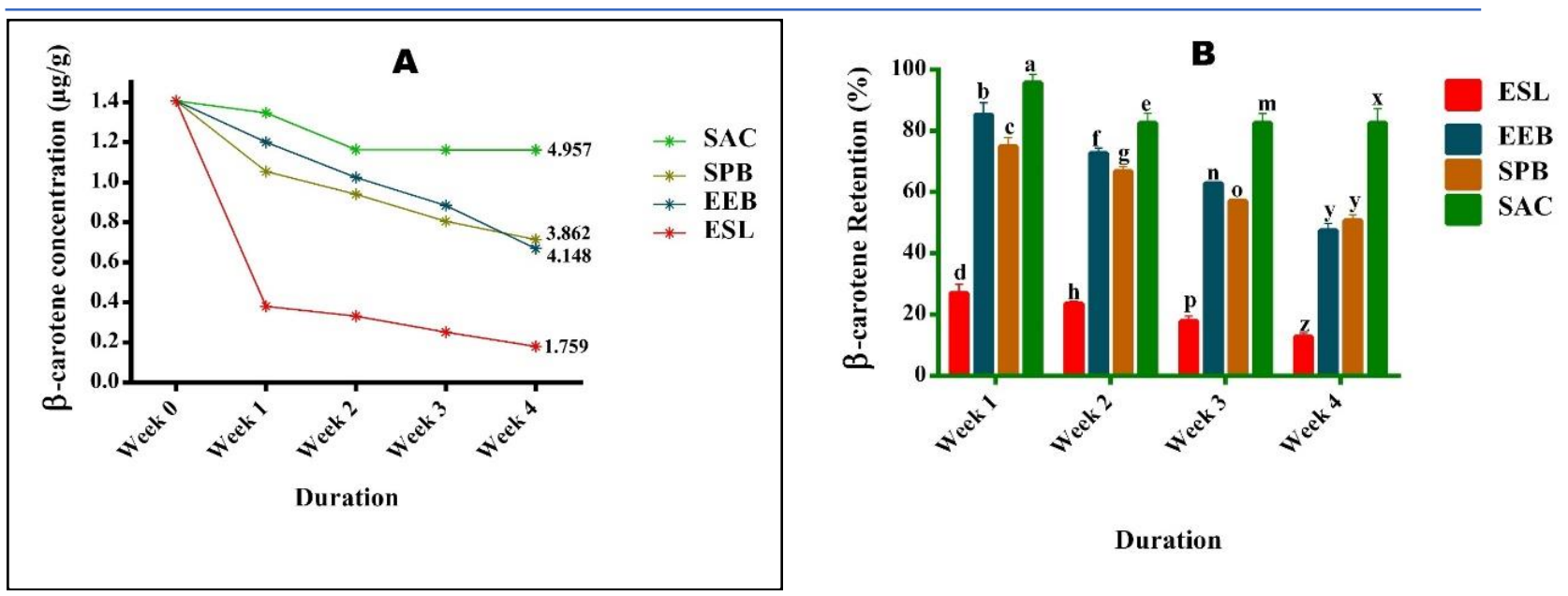

Figure 4: The stability profile of $\beta$-carotene in TMS 01/1371 gari (A) showing the total area under curve of exposure to $35-45^{\circ} \mathrm{C}$ sunlight (ESL), exposure of 60 watts electric bulb light (EEB), storage in black polyethylene bag $(S P B)$ and storage in air-tight aluminum container $(S A C)$ over a 4 week period. The area under curve of each line is directly proportional to the stability of $\beta$-carotene in the biofortified gari. Comparison of the weekly retention of $\beta$-carotene $(B)$ in all the experiments was done using ANOVA (Post hoc: Bonferoni test; $p=0.05)$. Bars with same alphabet within each week are non-significantly $(p>0.05)$ different from each other.

\subsection{Retention (\%) of $\beta$-carotene: TMS 01/1412 gari versus TMS 01/1371 gari}

The percentage retention of $\beta$-carotene in gari processed from TMS 01/1412 was compared with that processed from TMS 01/1371 at the fourth week of the experiment (Figure 5). There was no statistical significant difference $(\mathrm{p}>0.05)$ in the retention of $\beta$-carotene between TMS $01 / 1412$ gari $(12.09 \pm 0.09 \%)$ and TMS $01 / 1371(12.79 \pm 1.20 \%)$ gari at the fourth week of exposure to $35-45^{\circ} \mathrm{C}$ sunlight (ESL). TMS $01 / 1412$ gari $(58.49 \pm 1.60 \%)$ showed significantly $(\mathrm{p}<0.05)$ higher retention of $\beta$-carotene than TMS $01 / 1371$ gari $(47.55 \pm 2.30 \%)$ at the fourth week of exposure to 60 watts electric bulb light (EEB). Similarly, at the fourth week of storage in black polyethylene bag (SPB), TMS 01/1412 gari $(61.87 \pm 2.5 \%)$ had significantly higher retention of $\beta$-carotene than TMS 01/1371 gari $(50.82 \pm 1.90 \%)$. However, at the fourth week of storage in air-tight aluminum container (SAC), TMS 01/1371 gari $(82.59 \pm 4.70 \%)$ portrayed significantly higher retention than TMS 01/1412 gari (60.24 $\pm 1.20 \%)$.

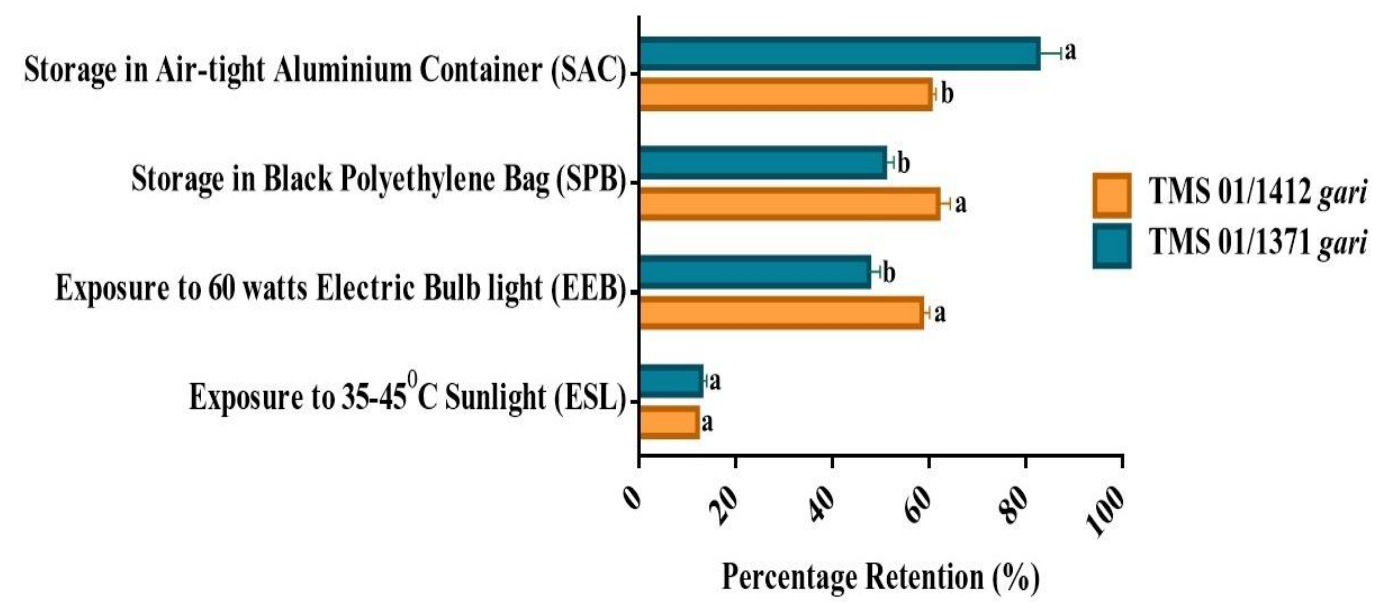

Figure 5: The overall (4 weeks) retention (\%) of $\beta$-carotene between TMS 01/1412 gari and TMS 01/1371 gari was compared through exposure to $35-45^{\circ} \mathrm{C}$ sunlight (ESL), exposure of 60 watts electric bulb light (EEB), storage in black polyethylene bag (SPB) and storage in air-tight aluminum container (SAC). Bars with same alphabet within each experiment are non- significantly $(p>0.05)$ different from each other. Comparison was done using Student's independent T-test at 5\% of the probability. 


\section{Discussion}

In Nigeria, during the day, food products are sold out-door under direct sunlight and in the presence of atmospheric oxygen. At night, food products are sold in-door under different kinds of artificial light source. Gari, a popular staple food, is among the food products that are traded in these harsh conditions. It is also certain that biofortified gari, a novel functional food, will be marketed in these harsh conditions. Therefore, this study partly investigated the influence of regular market selling conditions on the stability and retention of $\beta$-carotene in two different biofortified gari types.

The huge significant reductions in the $\beta$-carotene concentrations of gari processed from the two varieties following exposure to $35-45^{\circ} \mathrm{C}$ sunlight (ESL) is a clear indication of the detrimental effects of light, atmospheric oxygen and high temperature on the nutrient $[10,15,16]$. Further, the reductions in the $\beta$ carotene content of the two biofortified gari types following ESL was maximum at first week of the exposure thus suggesting that high temperature $\left(35-45^{\circ} \mathrm{C}\right)$ influenced the degradation of the nutrient. Moreover, an increase in degradation rate of $\beta$-carotene in gari as a result of short-term exposure to increasing temperatures above $30^{\circ} \mathrm{C}$ has previously been documented [13]. Several reports have also documented the detrimental effect of high temperature on $\beta$-carotene in various foods $[17,18]$. It is also possible that light generated from the sun in combination with atmospheric oxygen potentiated the degradation of $\beta$-carotene in the biofortified gari. These factors may have accounted for the lowest retention of $\beta$-carotene in the two biofortified gari types (TMS 01/1412 and TMS 01/1371) at the fourth week of exposure to sunlight.

On the other hand, the influence of exposure to 60 watts electric bulb light (EEB) on $\beta$-carotene in the two biofortified gari types were investigated. Although there were progressive reductions in the $\beta$-carotene content of the two biofortified gari types over the four weeks period of exposure, EEB portrayed a better stability and retention than ESL. As a possible mechanism, it can be suggested that the light generated by the 60 watts bulb in combination with in-door oxygen may be the major catalyst for the degradation of the nutrient. This implies that selling biofortified gari under the illumination of artificial lights may have minimal but progressive detrimental effects on the nutrient over time. While the common nutrient degrading factors between ESL and EBB appears to be light and oxygen, it can be suggested from this study that temperature seemingly served as a major catalyst for the higher degradation of the nutrient in ESL as compared with EBB. Although Bechoff et al. [13] had previously demonstrated the effect of varying temperature on carotenoids in biofortified gari placed in an incubator, the results from this study provide a real-life situational evidence of the detrimental effects of temperature variations of daily sunlight (ESL); as well as the effect of an artificial light source (EEB) on the nutrient. In addition, results from this study also indicate that a combination of both day and night market selling conditions may cause higher degradation of $\beta$ carotene in the biofortified gari.

Till date, very little research has been done on the stability and retention of $\beta$-carotene in biofortified gari during storage. Although the effect of an unconventionally developed system of storage on carotenoids stability and retention in biofortified gari was initially demonstrated by Bechoff et al. [13], there is currently no information on the effects of conventional methods of storage on the nutrient. The present study, in addition, investigated the influences of storage in black polyethylene bag (SPB) and storage in air-tight aluminum container (SAC) on the stability and retention of $\beta$-carotene in two different biofortified gari types. In Nigeria, SPB is a conventional method of packaging and/or storing purchased food products while SAC is mostly used to store oxygen labile foods or to prevent the entry of contaminants or food insects. The two methods of storage (SPB and SAC) appears not to totally halt the degradation of $\beta$-carotene in the two biofortified gari types. This is a justification of fact that pro-vitamin A carotenoids are highly unstable. SPB and SAC were used in this study to factor out the problem of light and oxygen penetration. The lower retention capacity of SPB compared to SAC may be influenced by the presence of more residual oxygen within the storage system. 
The two biofortified gari types used for this study show marked differences in their stability and between all the experiments using the area under curve (AUC) analysis. The AUC analysis revealed that the stability of $\beta$-carotene in TMS 01/1412 gari ranged from ESL (least stable) to SPB (most stable) whereas the stability of $\beta$-carotene in TMS 01/1371 gari ranged from ESL (least stable) to SAC (most stable). The differences in the stability and retention capacities between the two biofortified gari across all the experiments may be attributed to genetic influences [15, 19, 20]. To further support this inference, Bechoff et al. [21] recently reported marked differences in the retention of carotenoids during production of biofortified gari from TMS 01/1371, 01/1412 and 01/1368 respectively. Further, results from this study also suggest that TMS 01/1371 gari viz a viz SAC portrayed the highest retention of $\beta$-carotene than of TMS 01/1412 gari. Our results is consistent with reports on the better stability and retention of $\beta$-carotene in TMS 01/1371 cassava products compared to those of other varieties [9, 22].

\section{Conclusion}

The influences of market selling conditions and storage methods on the stability and retention of $\beta$-carotene were investigated in the two biofortified gari types. Exposing the two biofortified gari types to sunlight (ESL), a day time market selling condition, showed the highest detrimental effect on the stability and retention of $\beta$-carotene in the two biofortified gari types. More also, exposing the two biofortified gari types to 60 watt electric bulb light (EEB), a night time market selling condition, had a moderate negative influence on the stability and retention of the nutrient. As a consequence, a combination of these two market selling conditions on the two biofortified gari types would be largely detrimental to the stability and retention of their $\beta$-carotene contents. Storage in black polyethylene (SPB) and air-tight aluminum container (SAC) though influenced better stability and retention but did not totally halt the degradation of the nutrient in the two biofortified gari types. SAC $(82.59 \%)$ portrayed a better retention of the nutrient than SPB $(60.24 \%)$ irrespective of the biofortified gari type. Overall, TMS 01/1371 gari retained more of the nutrient in all the experiments than TMS 01/1412 gari.

\section{Declarations}

\subsection{Study Limitations}

This study was limited to the influences of market selling conditions and storage methods on $\beta$-carotene stability and retention in biofortified gari within the duration of 4 weeks.

\subsection{Acknowledgments}

We want to thank the Deputy Registrar of the Dominican University, Ibadan, Oyo state, Nigeria, Rev. Fr. Samuel Onyiba, for recommending and introducing us to HarvestPlus Nigeria. We thank the country manager of HarvestPlus Nigeria, Dr. Paul Ilona, for providing the propagative stems of the two biofortified cassava varieties used for this study. We thank those who assisted with the planting and processing of the biofortified cassava: Mr. Isaac Okeke Onyiba, Mr. P.C. Anyanwu, Mrs. Kate Anyanwu, Mrs. Ezinwanne Philip Tayo, Miss Echefulachi Anyanwu and Miss Chikaodi Anyanwu. We express our gratitude to those who assisted with the laboratory analysis and data collation: Miss Adaolisa Igboekwe, Mr. Samuel Ndukwe and Miss Nwamaka Cynthia Ikeji. We sincerely thank the Department of Biochemistry, Michael Okpara University of Agriculture, Umudike, Abia state, Nigeria for providing the laboratory assistance and equipment used for this study.

\subsection{Competing Interests}

The authors declared that no conflict of interest exists in the publication of this work.

\section{How to Cite this Article:}

C. Onyiba and S. Egba, "Market Selling Conditions and Storage Methods Influences $\beta$-carotene Stability and Retention in Biofortified Gari”, Adv. J. Grad. Res., vol. 8, no. 1, pp. 58-67, Apr. 2020. https://doi.org/10.21467/ajgr.8.1.58-67 


\section{References}

[1] WHO (World Health Organization). Micronutrient Deficiencies. 2018a.

[2] WHO (World Health Organization) Guideline: Fortification of rice with vitamins and minerals as a public health strategy. 2018b.

[3] Adugna Bayata. Review on Nutritional Value of Cassava for Use as a Staple Food. Science Journal of Analytical Chemistry. Vol. 7 , No. 4, pp. 83-91 September, 2019.

[4] Dixon, M. Response of Cassava Genotypes to Four Biotic Constraints in three Agro-Ecologies of Nigeria. African Crop Sci. J., Vol 10 No 1 pp 11-22, January, 2002.

[5] FAOStat (2018) Statistical database. Cassava production in 2016, Rome: Food and Agriculture Organization. Retrieved April 11, 2020.

[6] Maziya-Dixon, B, Akinyele, IO, Oguntona, EB, Nogkoe, S and Harris, E. Nigeria Food Consumption and Nutrition Survey 2001 2003 Summary. International Institute of Tropical Agriculture, ISBN 978131221 1. 2004.

[7] L. Ola, H. Rihana, N. Siew et al., "Identification of aromatic compounds and their sensory characteristics in cassava flakes and garri (Manihot esculenta Crantz, CyTA)," Journal of Food, vol. 14, no. 1, pp. 154-161, 2016.

[8] Escobar, A., Dahdouh, L., Rondet, E., Ricci, J., Dufour, D., Tran, T. \& Delalonde, M. Development of a novel integrated approach to monitor processing of cassava roots into gari: Macroscopic and microscopic scales. Food Bioprocess Technology, Vol 11, pp 13701380. May, 2018.

[9] Bechoff A, Chijioke U, Westby A, Tomlins KI. 'Yellow is good for you': Consumer perception and acceptability of fortified and biofortified cassava products. PLoS ONE Vol 13 No 9. Sepetember, 2018.

[10] Aragón, I. J., Ceballos, H., Dufour, D., \& Ferruzzi, M. G. Pro-vitamin A Carotenoids Stability and Bioaccessibility From Elite Selection of Biofortified Cassava Roots (Manihot esculanta, Crantz) Processed to Traditional Flours and Porridges. Food \& Function. August, 2018.

[11] Mugode, L., Ha, B., Kaunda, A., Sikombe, T., Phiri, S., Mutale, R., De Moura, F.F. Carotenoid retention of biofortified provitamin A maize (Zea mays L.) after Zambian traditional methods of milling cooking and storage. J. Agric. Food Chem. Vol 62, pp 63176325. July, 2014.

[12] Bechoff, A., Tomlins, K.I., Dhuique-Mayer, C., Dove, R., Westby, A. On-farm evaluation of the impact of drying and subsequent storage on the carotenoid content of orange-fleshed sweet potato. Int. J. Food Sci. Technol. Vol 46, 52-60. January, 2011.

[13] Bechoff, A., Chijioke, U., Tomlins, K. I., Govinden, P., Ilona, P., Westby, A., \& Boy, E. Carotenoid stability during storage of yellow gari made from biofortified cassava or with palm oil. Journal of Food Composition and Analysis, Vol 44, pp 36-44. June, 2015.

[14] Umeh SI and Ogbuagu AS. A Handbook of Laboratory Analysis in Agriculture and Biological Sciences. Fab Anieh Nig. Ltd., Pp. 44 - 47. 2012. ISBN: 978-978-8415-49-7.

[15] Carvalho, L. J., Oliveira, A. G., Godoy, R. O., Pacheco, S., Nutti, M., de Carvalho, J. V., ... Fukuda, W. (2012). Retention of total carotenoid and $\beta$-carotene in yellow sweet cassava (Manihot esculenta Crantz) after domestic cooking. Food \& Nutrition Research, 56 (1), 15788. March, 2012.

[16] Vásquez-Caicedo, AL, Schilling, S, Carle, R and Neidhart, S., (2007). Impact of Packaging and Storage conditions on Colour and $\beta$ carotene Retention of Pasteurized Mango Puree. European Food Research and Technology; Vol 224, pp 581-590. March, 2007.

[17] Bechoff, A, Dhuique-Mayer C, Dornier M, Tomlins K, Boulanger R, Dufour D and Westby A. Relationship Between the Kinetics of $\beta$-carotene Degradation and Formation of Nor-isoprenoids in the Storage of Dried Sweet Potato Chips. Food Chemistry; Vol 121 pp 348-357. July 2010.

[18] Olarewaju M. Oluba. Nutrient and antinutrient retention in indigenous white cassava gari and provitamin A biofortified yellow cassava gari fermented over different time periods. Asian J. Agric. Biol. Vol 8 No1 pp 44-51. February, 2020.

[19] Maroya NG, Kulakow P, Dixon AG, Maziya-Dixon BB. Genotypex Environment Interaction of Mosaic Disease, Root Yields and Total Carotene Concentration of Yellow-Fleshed Cassava in Nigeria. International Journal of Agronomy. Volume 2012, Article ID 434675, 8 pages. May, 2012.

[20] Peprah, B.B., Parkes, E., Manu-Aduening, J. et al. Genetic variability, stability and heritability for quality and yield characteristics in provitamin A cassava varieties. Euphytica 216, 31. January, 2020.

[21] Bechoff A, Tomlins KI, Chijioke U, Ilona P, Westby A, Boy E. Physical losses could partially explain modest carotenoid retention in dried food products from biofortified cassava. PLoS ONE Vol 13 No 3: e0194402. March, 2018.

[22] Eyinla, T. E., Maziya-Dixon, B., Alamu, O. E., \& Sanusi, R. A. Retention of Pro-Vitamin A Content in Products from New Biofortified Cassava Varieties. Foods, Vol 8 No 5, pg 177. May, 2019.

Publish your books with AIJR publisher-

- $\quad$ Publish with ISBN and DOI.

- Publish Thesis/Dissertation as Monograph.

- $\quad$ Publish Book Monograph.

- $\quad$ Publish Edited Volume/ Book.

- $\quad$ Publish Conference Proceedings

- $\quad$ Retain full copyright of your books.

Submit your manuscript at books.aijr.org
Publish your research article in AIJR journals-

- Online Submission and Tracking

- $\quad$ Peer-Reviewed

- $\quad$ Rapid decision

- Immediate Publication after acceptance

- Articles freely available online

- $\quad$ Retain full copyright of your article.

Submit your article at journals.aijr.in 